drenched by waves or spray, encrusted with irritating salt, and develop boils and sores, parched throats, and swollen tongues, lose strength when it is most needed, suffer cramps, sleeplessness, and heartbreaking fatigue. On top of these physical burdens they may suffer fear, loneliness, a sense of inadequacy, bad dreams, muscular incoordination, delusions, and hallucinations. The last can be expected when there has been lack of sleep for 48 hours, especially in seriously adverse circumstances, and they take such bizarre forms as beckoning figures inviting the survivor to leave his situation of plight for promised comfort.

In extreme environments on land-for example, when lost in desert or jungle-the victim of hallucinations may wander aimlessly or creep into a hole to escape the immediate harassment. But at sea to leave his raft or boat is to drown. Furthermore the cold of the northern waters can kill in minutes, while in the warmer tropical and subtropical waters sharks are waiting. They stay with lonely survivors knowing that sooner or later one will slip over the side. Sometimes they have a role in the hallucinations, being part and parcel of the tempting fantasy. Wise and well-trained mariners know this and are conditioned to ignore their hallucinations.

The importance of morale and mental training for people who undertake challenging adventures needs emphasizing. Experience has shown that when they face serious stress the inexperienced ones may suffer fear and panic, become violent, and throw their lives away. The more seasoned ones will endure the hardship. But if despair and fatigue prevail they may slip gently over the side and swim away or fall prey to their hallucinations. In one reported incident an exhausted seaman told his companions that he was "chucking it in," shook their hands, and quietly left the raft. The others were too weak to restrain him. But many have survived these mental ordeals and helped their companions to do so by their example and control. Years of disciplined service at sea have stressed the importance of routine, of filling idle hours with enforced activity and interest, of songs and stories while strength lasts, and later prayer. The hours of darkness are the worst, and lashing to a seat or mast may keep the survivor in his boat. If the mind does not break, the body will take an astounding degree of punishment. Those responsible for the training of secret agents know this well.

\section{Prognosis for Babies Born to Diabetic Mothers}

The incidence of detected diabetes mellitus is probably increasing and likely to continue to do so. ${ }^{1}$ Detection drives have shown in Western Europe and in the U.S.A. an incidence of about 13 per 1,000 population, of whom half were previously not known to have the disease. With careful control during pregnancy the high rates of stillbirth and neonatal death associated with maternal diabetes can be considerably reduced, but little is yet known about the progress of the surviving children. A reduction in perinatal mortality is all the more gratifying if it can be shown that there is no excessive morbidity among the survivors.

J. W. Farquhar ${ }^{2}$ has now reported the outcome of all viable pregnancies in diabetic mothers at the Simpson Memorial
Maternity Pavilion in Edinburgh between 1948 and 1966. The group comprised 329 infants, and follow-up was attempted on the 260 who survived the neonatal period. That $98 \%$ were traced is surely a remarkable achievement.

Two survivors are now themselves diabetic, an incidence $\vec{z}$ of 0.77 per 100 . This figure is more than 20 times greater $\stackrel{\mathbb{Q}}{\stackrel{2}{ }}$ than would be expected for the general child population in $\subseteq$ Scotland. P. White ${ }^{3}$ found that 9 of every 100 children in $\underset{\vec{D}}{\vec{F}}$ her Boston study were already diabetic by adolescence, but $\vec{T}$ this high figure was not repeated in surveys from Sweden and Australia. Two others of the Edinburgh children have older siblings who are already diabetic. Sir John Peel ${ }^{1}$ has $\stackrel{\mathbb{\Omega}}{\stackrel{\Omega}{2}}$ pointed out that the assessment of the true incidence of is diabetes among survivors may not be completed for some $\vec{\theta}$ years yet, since the maximum age incidence of the disease is in the late fifties and insulin had been in use only since 1922 .

Farquhar searched diligently for congenital abnormalities $\frac{D}{O}$ in the stillbirths, in the neonatal and later deaths, and among the survivors. Lethal malformations were present in $1.5 \%$ of all births. The incidence of significant malformations was $8.8 \%$ in all who survived the first month. He had previously ${ }^{4}$ compared the incidence of abnormalities up to the age of 12 years in 135 children of diabetic mothers who survived the 9 neonatal period with that in a group of carefully matched controls. There was little difference in the incidence of abnormality in the two groups. C. Watson, ${ }^{5}$ in a similar study from London, found no significant difference in incidence $\bar{g}$ betwen her maternal-diabetic and control groups, but found a tendency for the congenital abnormalities associated with maternal diabetes to be more severe. On the other hand, L. M. Pedersen and colleagues ${ }^{6}$ found in their series from Copenhagen that the overall incidence of abnormality was three times as high as that in the general population. White ${ }^{3}$ reported the remarkably high incidence of $13 \%$ in contrast to an expected incidence in Boston of $1.8 \%$. The principal types of abnormality found have shown considerable variation in the different series. This is to be expected, because the relative incidence of different congenital abnormalities varies considerably throughout the world and indeed in different parts of Great Britain. ${ }^{7}$

The heights and weights of Farquhar's survivors are of considerable interest, especially in view of the large size of these infants at birth. The present heights and weights of most of them fall within the normal range, but excessive weight for height was a common finding. This was not, how- 9 ever, noted in either of the two children already themselves $N$ diabetic.

Farquhar has given an encouraging prognosis, and this is something that doctors can pass on to the diabetic mothers in their care. It is well known that the successful outcome of pregnancy in the diabetic mother depends on close co-operation among physician, obstetrician, and paediatrician. But 0 the patient herself must be willing to accept the advice offered her, and an encouraging prognosis can surely be a help here.

1 Peel, J., in Recent Advances in Obstetrics and Gynaecology, 1966, 11 th ed., ed. J. Stallworthy and G. Bourne. London, Churchill.

- Farquhar, J. W., Archives of Disease in Childhood, 1969, 44, 36.

3 White, P., in The Treatment of Diabetes Mellitus, 1959, 10th ed., p. 690, ed. E. P. Joslin, H. F. Root, P. White, and A. Marble. Philadelphia, Lea and Febiger ; London, Kimpton.

- Farquhar, J. W., in Recent Advances in Paediatrics, 1965, 3rd ed. p. 121, ed. D. Gairdner. London, Churchill.

5 Watson, C., Archives of Disease in Childhood, 1968, 43, 746.

- Pedersen, L. M., Tygstrup, I., and Pedersen, J., Lancet, 1964, 1, 1124.

7 Butler, N. R., Alberman, E. D., and Schutt, W. H., in Perinatal Problems, 1969, ed. N. R. Butler and E. D. Alberman. Edinburgh, Livingstone. 